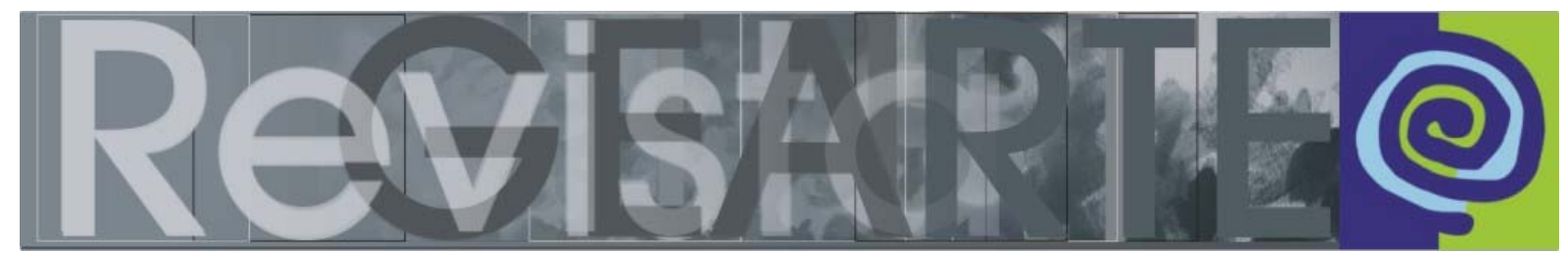

ISSN 2357-9854

\title{
Os novos discursos sobre arte, agora escritos pelos artistas
}

\author{
João Paulo Queiroz (UL - Portugal)
}

\begin{abstract}
RESUMO
A experiência do autor na conceção e organização, em Lisboa, de quatro congressos internacionais (os congressos CSO ou "Criadores Sobre outras Obras") onde artistas escrevem sobre as obras de outros artistas e também na gestão de periódicos acadêmicos correspondentes ("Estúdio", "Gama", "Croma"), permite questionar as mudanças no campo artístico, na atualidade. Em particular, observa-se o diferente posicionamento do artista com uma educação mais exigente, e uma prática mais interveniente, com o seu suporte incluindo o público, misturando a curadoria, e a programação cultural, dentro do contexto discursivo caraterizado pela emergência de novas discilplinas no campo acadêmico.
\end{abstract}

PALAVRAS-CHAVE

CSO'2015. Revista Estúdio. Revista Gama. Revista Croma. Artistas.

\section{ABSTRACT}

The author's experience on organizing, in Lisbon, four international congresses, where artists present papers on other fellow artists' work (the "CSO" congresses), and also the experience on the managing of three academic journals ("Estúdio", "Gama", "Croma") allowed some prospective thinking on the changes on the contemporary art scene. Artists today seek much higher levels on art education - more and more usually at a postgraduate level. Artists play also new roles, on managing art platforms and curating art projects, and this adds up to a new cultural landscape. KEYWORDS

CSO'2015. Estúdio Journal. Gama Journal. Croma Journal. Artists.

\section{Introdução}

Neste artigo explora-se a articulação entre os novos paradigmas do discurso artístico que emergiram nos últimos anos e a proposta lançada pelos congressos de Lisboa CSO (Criadores Sobre outras Obras), os CSO'2010, 2011, 2012, 2013, 2014, 2015 (Queiroz, 2010; 2011; 2012; 2013; 2014) e os respectivos periódicos adjacentes, as revistas: Estúdio, Gama e Croma. Faz-se uma revisão da evolução dos congressos na sua trajetória de consolidação, para depois relacioná-los com as diferentes mudanças do espaço público no que respeita à arte.

Particularmente, serão caracterizadas as alterações no modo como o artista se relaciona com o seu trabalho, ao operar mais perto do público, junto à disseminação e à proposta de plataformas, para ter uma ação mais informada, 
fazendo uso de formação pós-graduada, num contexto de crescente pluralismo nos circuitos legitimadores sobre a arte e seus discursos.

\section{Alterações no campo artístico}

$\mathrm{Na}$ experiência dos congressos CSO lança-se a exigência de critérios de submissão e normas de redação próximas das ciências humanas. Há alterações essenciais em curso, que tornaram possível a reivindicação de um espaço discursivo e de um campo operativo diferentes daqueles até aqui verificados.

Poderei relacionar algumas alterações importantes no posicionamento do artista face ao seu campo de intervenção, no sentido da sua expansão: (1) mudança no discurso sobre arte, chegando ao fim a hegemonia da História da Arte através da emergência de novas disciplinas e métodos; (2) mudança na formação dos artistas, passando-se da exigência da graduação à exigência da pós-graduação, e integrando a formação ao longo da vida; (3) mudança da ação dos artistas, passando-se à arte "expandida" (KRAUSS, 1979), com uma maior presença do artista como agenciador e curador.

Há alterações no diedro do campo artístico em todas as suas dimensões: por um lado, na dimensão do autor, cada vez mais informado e competente na verbalização sobre a arte, por outro lado, na dimensão dos discursos sobre a arte, mais poliédricos e integrando as mudanças da pós-modernidade e, numa dimensão não menos importante, no lado da disseminação da arte, com um grande envolvimento do artista nas plataformas de agenciamento, antes delas tão ausente.

Pode-se dizer que é o próprio artista que se expandiu, ocupando espaços de formação, de intermediação, e de discurso, respectivamente.

De um modo um pouco mais detalhado apontam-se, a seguir, alguns momentos-chave nesse processo, enfocando: ciências sociais, formação artística, artista intermediador, alterações contextuais nos discursos dominantes das mídias. 


\subsection{Ciências humanas}

As ciências sociais têm vindo a debruçar-se sobre os temas artísticos, renovando as abordagens: áreas como a antropologia cultural, a linguística, a semiologia, a psicologia social, a que se acrescentam os cultural studies.

Verificou-se uma passagem de objeto entre áreas disciplinares, no contexto da pós-modernidade. É a transição entre os objetos exclusivos da História da Arte para os objetos de estudo da sociologia (BECKER, 2010), da psicologia social (MOSCOVICl, 1961), da antropologia (LÉVI-STRAUSS, 1958; BOURDIEU, 1989; 2003), e da retórica/semiologia (BARTHES, 1988), integrando no seu objeto as manifestações da cultura pop (HOGGART, 1958; WILLIAMS, 1957; HALL; WHANNEL, 1964), que em conjunto com a problematização da indústria cultural pelos teóricos da Escola de Frankfurt vieram permitir uma transformação epistemológica fundamental: a queda da diferenciação entre cultura erudita e cultura popular, como pressentira W. Benjamin quando aponta o fulcro na reprodutibilidade e na divisão do trabalho, referindo que "a reprodutibilidade técnica da obra de arte altera a relação das massas com a arte. Reacionárias, diante, por exemplo, de um Picasso, transformam-se nas mais progressistas frente a um Chaplin" (BENJAMIN, 1992, p. 100).

Se é verdade que a História da Arte se fundamenta na essencialidade do que é erudito, trazida pela própria definição de "arte", então ela encontra-se potencialmente desprovida de assunto, no que respeita a algumas manifestações contemporâneas e, decerto, no que respeita a toda a sua tecida complexidade.

É nesse contexto de reposicionamento de referências e de alteração de paradigmas que emergem as perspetivas interdisciplinares contemporâneas dos Estudos Culturais. Resultam beneficiados os pontos de vista integradores, as disciplinas pós-modernas e as aproximações interdisciplinares como as que os estudos sobre Cultura Visual vêm produzindo, paralelamente à progressiva perda da hegemonia discursiva tradicional, construída em torno do paradigma da arte. 


\subsection{Formação artística}

Concomitantemente às modificações de referencial do discurso sobre a arte, o artista também sofre alterações constantes no que respeita à sua formação. Se outrora o ensino artístico se radicava em academias mais ou menos modernistas, em que a lógica das vanguardas era o combustível para um posicionamento geracional e para uma estratégia de inovação - em que "a Escola" era uma entidade imóvel perante a qual o jovem artista reagia-, hoje a situação é bem diferente.

Hoje um jovem em formação começa por cruzar várias escolas na graduação, por via de programas de mobilidade como o ERASMUS, o Ciências Sem Fronteiras, ou o PLI (Programa de Licenciaturas Internacionais da CAPES/Brasil), para além das bolsas de mobilidade privadas. Não raramente o jovem em formação frequenta múltiplos ateliers e workshops em paralelo à graduação. Nas escolas de artes, ele pode compor muitas vezes o seu currículo, estabelecendo um percurso de disciplinas de sua própria iniciativa, multiplicando experiências e influências.

Finda a graduação, a formação ao nível de mestrado é percebida socialmente como cada vez mais indispensável, mas com uma nuance: é normal o mestrado ser feito em local diferente da graduação.

Enfim, o que sucede é que o artista tem, por um lado, uma formação mais longa e, por outro, uma habilitação e uma literacia mais aprofundada, com competências para apresentar trabalhos escritos, ensaios e teses perante júris acadêmicos, as quais são incentivadas de várias formas. Igualmente, a formação é mais variada e o paradigma da revolta contra a Academia perdeu o seu sentido.

O artista de hoje complementa a graduação com formação suplementar e deslocalizada. $O$ doutoramento já surge no seu horizonte naturalmente. As suas competências discursivas, linguísticas e metodológicas estão num outro patamar. 


\subsection{Artista intermediador}

A ação dos artistas tem se tornado mais interventiva. Os artistas têm desempenhado papéis de intermediação, ao organizarem e gerirem espaços alternativos de disseminação e ao expandirem a atividade para além do atelier. Das oficinas cooperativas de produção de múltiplos, passando pela autoedição de livros de artista, e continuando na organização de novos espaços públicos de circulação underground, há um conjunto de novas funções associadas à circulação e à ação social e cultural. A área do criador emancipou-se do paradigma das vanguardas, enveredando pela interação, e a nova identidade incorpora um novo papel como pivô.

Hoje um artista gere acontecimentos, além de gerir objetos. Gere contatos e plataformas de disseminação. Gere projetos editoriais, galerias, residências, associações, ateliers. O artista tornou-se um gestor cultural com competências curatoriais.

\section{Alteração contextual das mídias}

A alteração do circuito socioeconômico provocada pelas novas tecnologias e pela crescente dependência, das mídias, da publicidade, no novo contexto do neoliberalismo globalizado, favorece os grandes grupos econômicos e a respectiva concentração em carteiras de títulos (jornais, revistas, emissoras de TV e rádio), reduzindo, por um lado, o número de interesses e de agentes e, aumentando, por outro, a especialização de títulos, fruto de estratégias de segmentação. As bancas encheram-se de publicações segmentadas por hábitos de consumo e suscetíveis de gerar publicidade especializada (por exemplo, revistas sobre carros transformados, jogos de computador, fotografia digital, cães, ou muitas outras, ou a multiplicidade que segue a mesma lógica de canais de televisão por assinatura ).

O novo paradigma das mídias é um limiar de amortização cada vez mais exigente pressionado por acionistas em grandes grupos cotados em bolsa (JHALLY, 1995). Os conteúdos terão de ser cada vez mais low-cost, e capazes de gerar grandes audiências. É uma paisagem onde a produção midiática se 
baseia em concursos e reality shows, isto no que diz respeito aos canais abertos. Nos canais pagos reina o conteúdo formatado segundo rotinas de especialização temática, em que não há surpresas ou espaço para inovação.

\section{Desaparecimento da crítica, emergência do curador}

Assim, as mídias adequam o conteúdo a temas suscetíveis de gerar retorno publicitário, dentro da eficácia da audiência. Aqui o espaço para a coluna de crítica de arte desaparece: a arte não gera anúncios. Mesmo o tamanho da agenda de eventos é reduzido aos principais. As páginas da imprensa passam a corresponder aos anúncios gerados pela atratividade da seção. Há páginas de cinema acompanhadas por anúncios de cinema; há páginas sobre percursos turísticos acompanhadas por anúncios de pacotes de viagens; há páginas sobre automóveis acompanhadas por anúncios de automóveis..

Hoje o crítico que escrevia em jornais é uma figura desaparecida. O setor sobre exposições, ou surge no âmbito de um serviço público cada vez mais cortado em tempo e em recursos, ou simplesmente deixa de existir.

Mas hoje o produtor de discurso, antes um crítico, é um curador. Esse produtor/organizador de discurso pode encontrar novos empregadores, sob a condição de modificar a sua ação. A nova relação mistura gestão de eventos, organização de shows, angariação de apoios, enquadrando-se normalmente em pequenas ou grandes instituições privadas.

Com essa mudança emerge também uma nova relação desse organizador do discurso com o mundo. Da redação de jornal, transita-se para o fim último do trabalho: o museu de arte contemporânea ou o evento de representação institucional (coleções de grandes grupos econômicos, bancos, seguros, junto com o comissariado de representações nacionais em eventos e exposições). Mas até o curador aceder a este patamar tem um trabalho intenso de legitimação no circuito, começando por pequenos eventos e, claro, por traçar relações de cumplicidade geracional com artistas.

Aqui reside uma das chaves que é o acesso e o conhecimento dos intervenientes das novas gerações. Por vezes, por especialização na prática de 
eventos, observa-se que alguns artistas têm, por relações pessoais e geracionais, mais acesso ao recrutamento de outros operadores artísticos do que os curadores e críticos exteriores às relações de companheirismo e de trabalho próximo.

Por outro lado, o mercado beneficia cada vez mais a juventude: os "jovens artistas", os "valores emergentes". São dinâmicas que se prendem com o retorno de investimento e com a especulação que atingiu o art world nas últimas décadas (THORNTON, 2010). A cotação de alguns artistas mais maduros subiu até patamares que, por um lado, estabelecem uma barreira de crença e de legitimação cada vez mais cavada entre artistas com circulação internacional e outros com menor ventilação e, por outro, a dinâmica do mercado de galerias e de feiras de arte faz com que um jovem promissor, devidamente enquadrado em coleções investidoras, permita ganhos mais elevados do que um seu colega mais maduro.

Será, neste contexto, muito difícil, ou quase impossível, começar uma coleção de arte com artistas, por exemplo, de algumas décadas atrás: os nomes da arte modernista encontram-se encerrados em coleções instituídas, como os museus. As obras que hoje circulam no mercado são normalmente obras menores ou de autoria duvidosa. As coleções foram consolidadas através de aquisições feitas no seu tempo. Este fato contribui para alimentar a pressão sobre o recrutamento de jovens: é uma pressão do próprio circuito econômico. Encontrar o próximo Damien Hirst, ou Takashi Murakami, poderá ser uma oportunidade verdadeiramente apelativa e que dita os valores em causa.

\section{A integração universitária}

Em paralelo, assistiu-se em diversos países da Europa e da América a integração de escolas de arte em universidades, inserindo os seus professores e alunos em redes exigentes de produção acadêmica, com organismos e programas de acreditação e indexação, de avaliação e de supervisão segundo referenciais científicos (FCT em Portugal, CAPES no Brasil, ANECA em Espanha, FIPSE nos EUA, CNRS em França, SECyT na Argentina, entre tantos 
outros) e com um incentivo continuado ao aperfeiçoamento e à eficácia da comunicação.

O professor de artes, além de criador, é hoje um professor universitário que responde a todas as exigências inerentes: o mestrado, o doutoramento, as avaliações periódicas, a monitorização da sua eficiência docente, os inúmeros relatórios e trabalhos produzidos, paralelamente à exigente orientação de teses e à docência em cursos de doutoramento, de mestrado e de graduação, não raramente em simultâneo.

Este é um clima em que a exigência sobre o operador artístico, agora professor universitário, se desdobra nas múltiplas possibilidades de definição do pesquisador, num caminho que está ainda a começar a ser traçado.

\section{A sequência dos congressos CSO' Criadores Sobre outras Obras}

Textos sobre artistas, produzidos por outros artistas.

Ao longo deste artigo, caracterizei as diversas dimensões que atualmente se conjugam para formar um espaço de oportunidade de produção de discursos de artistas sobre a obra de outros artistas - discursos informados e de qualidade.

Os congressos CSO', "Criadores Sobre outras Obras," organizados pela Faculdade de Belas Artes da Universidade de Lisboa, trouxeram um desafio: enviamos, por chamada de trabalhos, o apelo aos criadores e artistas graduados, para que apresentassem, em ambiente de congresso e sob o formato de comunicação, a sua perspectiva sobre a obra de seus colegas de profissão.

Estabelecemos como campo de intervenção o eixo latino-americano, aprofundando um ambiente linguístico (português e espanhol) e, ao mesmo tempo, provocando um descentramento discursivo alternativo ao anglocentrismo.

As comunicações através da rede possibilitaram uma razoável eficácia na disseminação da chamada mediante um trabalho minucioso de levantamento de agentes ativos no campo da arte e no campo da formação artística avançada. 
Quando idealizamos o CSO em 2009 e começamos a organizar as chamadas para a primeira edição, em 2010, esperávamos, sem muitas pistas sobre o seu impacto, talvez menos de 20 palestrantes. Esse modelo não tinha sido antes experimentado, não havia termo de comparação. Um congresso dirigido a artistas, e desafiando comunicações em formato acadêmico sobre outros artistas, é talvez um conceito diferente.

Afinal, recebemos por correio eletrônico 79 submissões, ficando aprovado, pela comissão científica um total de 68 comunicações. O congresso foi um momento surpreendente, pela sua dimensão e abrangência, ao princípio inesperadas. Tivemos boa representação da Espanha e dos diversos estados do Brasil, além de Portugal e do Peru.

No II CSO'2011, o congresso recebeu 130 submissões, ficando aprovadas 97 comunicações, entre muitos outros eventos paralelos. Introduziram-se como critérios de admissão a exploração de obras de artistas menos conhecidos, de qualidade, junto com a revelação de obras e autores oriundos dos países de expressão linguística portuguesa ou castelhana.

Um ano depois, no III CSO'2012, foram recebidas 140 submissões e aprovadas ao congresso 106 comunicações. Pudemos alargar o número de escolas de arte que apresentaram pesquisadores de um modo muito significativo.

Em 2013, recebemos mais de 217 submissões e aprovadas 147 comunicações, num leque crescente de participação. O mesmo grau de participação foi observado em 2014 e em 2015.

Este congresso deu também origem a periódicos acadêmicos, primeiro a revista internacional "Estúdio" (ISSN: 1647 - 6158, e-ISSN: 1647-7316), com sete números publicados, e depois as revistas internacionais "Gama, estudos artísticos" (ISSN 2182-8539) e "Croma, estudos artísticos" (ISSN 2182-8547), com dois números publicados cada uma. A revista Estúdio está indexada na coleção SciELO/Portugal. Todas as revistas estão indexadas em bases internacionais (Ex. Figura 1). 


\section{Reflexões finais}

O sucesso dessas iniciativas, congressos, revistas, atas, publicações acadêmicas, deve ser enquadrado nos dados contextuais apresentados.

Existe um conjunto de novas aptidões com que os artistas se municiaram, tornando o seu discurso sobre arte informado, consistente e credível. Há um maior investimento na diversificação da formação e também na continuidade desta formação ao longo de diversas etapas. Há maior circulação internacional na formação. Há um novo paradigma de intervenção do artista, em que este chama a si a intermediação e a gestão, adotando posições curatoriais, tanto do seu trabalho como da gestão de coletivos e de iniciativas. Há uma exigência intelectual no campo das ciências humanas, que retirou a hegemonia discursiva à história da arte. Há também um contexto crescente de expectativas discursivas dos próprios artistas, materializado na sofisticação da comunicação e na adoção dos protocolos das ciências humanas: é o espaço do congresso, da revisão por pares, da revista com conselho editorial, das plataformas de comunicação formais e assessoradas na qualidade acadêmica.

André Malraux (2011) anteviu o mundo como um Museu Imaginário, museu sem paredes. Malraux antecipava o museu sem hierarquia, sem centralidade, sem narrativas induzidas por historicismos ou eurocentrismos. Antecipava um espaço de referencialidade em que não importam as obras, mas o seu conhecimento: antecipava uma rede, uma relação entre espectadores e imagens, em que a reprodução desempenharia um papel libertador.

Cada artista, cada homem, poderá compor o seu Museu, o seu imaginário. É este um dos caminhos que se trilharam, tanto no Congresso CSO, como no panorama das artes em geral: abrir o museu imaginário dos artistas, por eles mesmos. O criador é um agente com uma autonomia renovada, e todos estes novos papéis a desempenhar. O "museu imaginário" ganha novas instâncias de existência, na sucessão destas atribuições e desafios a que o artista do nosso tempo é cada vez mais chamado a desempenhar. 
Figura 1 - O número 4 da Revista Estúdio, Artistas Sobre outras Obras, dedicada ao tema "corpo." Capa baseada em Fina Miralles, "Dona-Arbre" da serie Translacions (1973). Fotografia b/n, acción: mujer y paisaje. Sant Llorenç de Munt, Espanha

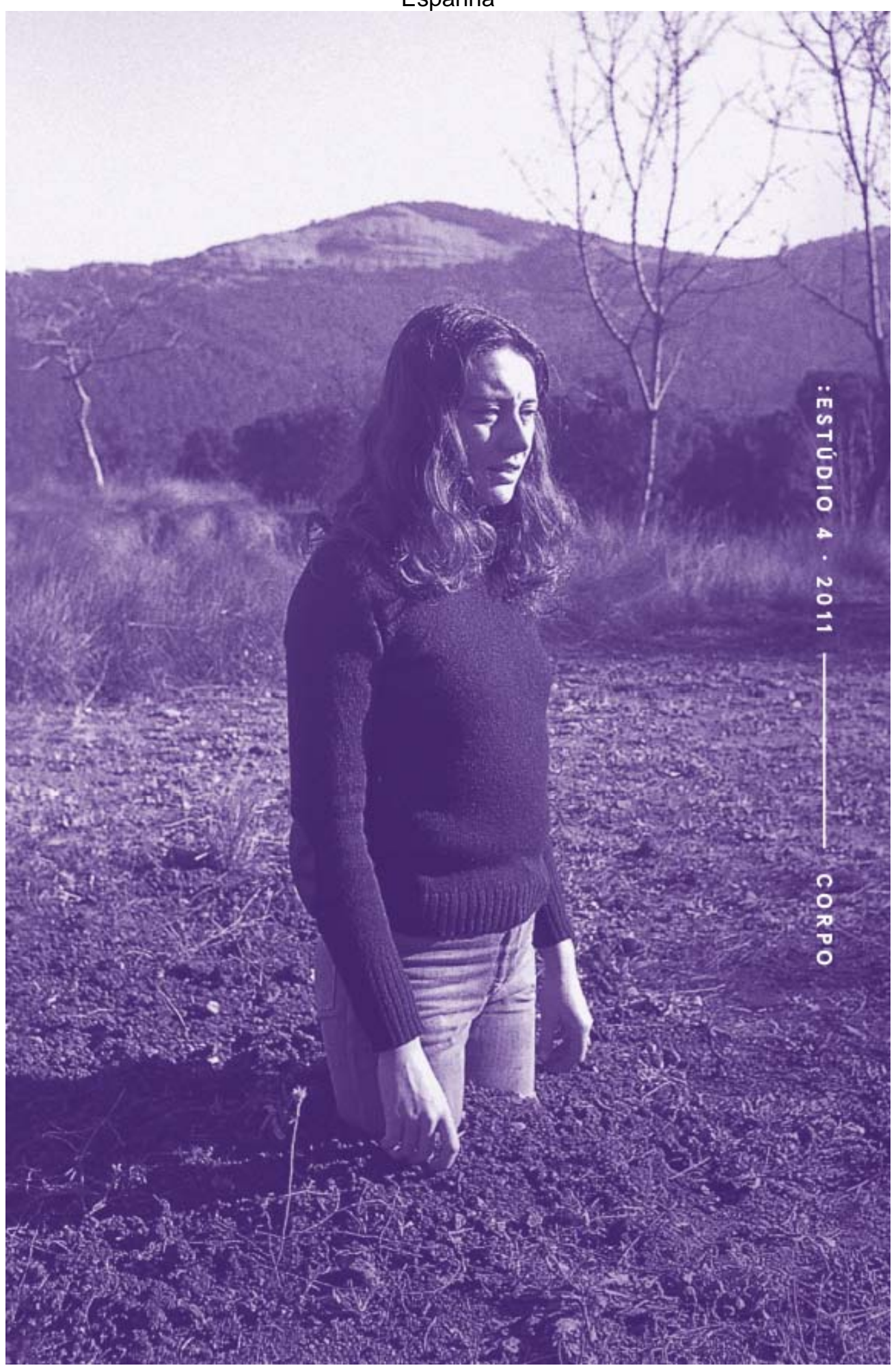

Fonte: Coleção Museu d'Art de Sabadell 


\section{Referências:}

BARTHES, Roland. Mitologias. Lisboa: Edições 70, 1988.

BECKER, Howard S. Mundos da arte. Lisboa: Livros Horizonte, 2010.

BENJAMIN, Walter. A obra de arte na era da sua reprodutibilidade técnica. In: Sobrearte, técnica, linguagem e política. Lisboa: Relógio D’Água, 1992. p. 71-113.

BOURDIEU, Pierre. O poder simbólico. Lisboa: Difel, 1989.

BOURDIEU, Pierre. O amor pela arte: museus de arte na europa e seu público, Porto Alegre: Editora Zouk, 2003.

CROMA, estudos artísticos. Lisboa: Faculdade de Belas-Artes da Universidade de Lisboa e Centro de Investigação e Estudos em Belas-Artes, 2013. Disponível em: <http://croma.fba.ul.pt/>

ESTÚDIO, artistas sobre outras obras. Lisboa: Faculdade de Belas-Artes da Universidade de Lisboa e Centro de Investigação e Estudos em Belas-Artes, 2010- (ISSN: 1647-6158 e ISSN: 1647-7316). Disponível em: <http://estudio.fba.ul.pt>

GAMA, estudos artísticos. Lisboa: Faculdade de Belas-Artes da Universidade de Lisboa e Centro de Investigação e Estudos em Belas-Artes, 2013- (ISSN 2182-8539). Disponível em: $<$ http://gama.fba.ul.pt>

HALL, Stuart; WHANNEL, Paul. The popular arts, London: Hutchinson, 1964

HALL, Stuart. The centrality of culture: notes on the revolutions of our time. In: THOMPSON, Kenneth (Ed.). Media and cultural regulation. London: Sage/Open University, 1997. p. 207-238.

HOGGART, Richard. The uses of literacy. Harmondsworth: Penguin Books, 1958.

JHALLY, Sut. Os códigos da publicidade. Porto: Asa, 1995.

KRAUSS, Rosalind. Sculpture in the expanded field, October, v. 8, Spring, p. 30-44, 1979. Disponível em: <http://www.onedaysculpture.org.nz/assets/images/reading/Krauss.pdf $>$. Acesso em: junho de 2015.

LEVI-STRAUSS, Claude. Anthropologie structurale. Paris: Plon, 1958

MALRAUX, André. O museu imaginário. Lisboa: ed. 70, 2011.

MOSCOVICl, Serge. La psychanalyse, son image et son public. Paris: P.U.F., 1961.

QUEIROZ, João Paulo. (Org.). CONGRESSO INTERNACIONAL CRIADORES SOBRE OUTRAS OBRAS: CSO, 1., 2011, Lisboa. Anais... Lisboa: Faculdade de Belas-Artes, Universidade de Lisboa Centro de Investigação e Estudos em Belas-Artes, 2010. Disponível em: <http://cso.fba.ul.pt/atas2010.htm> Acesso em junho de 2015.

QUEIROZ, João Paulo. (Org.). Quando os criadores apresentam obras de outros criadores. CONGRESSO INTERNACIONAL CRIADORES SOBRE OUTRAS OBRAS: CSO, 2., 2011, Lisboa. Anais... Lisboa: Faculdade de Belas-Artes, Universidade de Lisboa Centro de Investigação e Estudos em Belas-Artes, 2011. Disponível em: <http://cso.fba.ul.pt/ACTAS _CSO2011.pdf> Acesso em junho de 2015.

QUEIROZ, João Paulo. (Org.). Artes em torno do Atlântico. CONGRESSO INTERNACIONAL CRIADORES SOBRE OUTRAS OBRAS: CSO, 3., 2012, Lisboa. Anais... Lisboa: Faculdade de Belas-Artes, Universidade de Lisboa Centro de Investigação e Estudos em Belas-Artes, 2012. Disponível em: <http://cso.fba.ul.pt/ACTAS_CSO2012.pdf> Acesso em junho de 2015.

QUEIROZ, João Paulo. (Org.). Emergências. CONGRESSO INTERNACIONAL CRIADORES SOBRE OUTRAS OBRAS: CSO, 4., 2013, Lisboa. Anais... Lisboa: Faculdade de Belas-Artes, Universidade de Lisboa Centro de Investigação e Estudos em Belas-Artes, 2013. Disponível em: <http://cso.fba.ul.pt/ACTAS_CSO2013.pdf > Acesso em junho de 2015.

QUEIROZ, João Paulo. (Org.). Arte Contemporânea: criatividade e hibridação. CONGRESSO INTERNACIONAL CRIADORES SOBRE OUTRAS OBRAS: CSO, 5., 2014, Lisboa. Anais... Lisboa: Faculdade de Belas-Artes, Universidade de Lisboa Centro de Investigação e Estudos em 
Belas-Artes, 2014. Disponível em: <http://cso.fba.ul.pt/ACTAS_CSO2014.pdf> Acesso em junho de 2015.

THORNTON, Sarah. Sete dias no mundo da arte. Lisboa: Arcádia, 2010.

WILLIAMS, Raymond. Working-class culture: the uses of literacy symposium. Universities and Left Review, v. 1, n. 2, Summer, 1957.

\section{João Paulo Queiroz}

Possui Curso Superior de Pintura pela Escola Superior de Belas-Artes de Lisboa. É Mestre em Comunicação, Cultura e Tecnologias da Informação pelo Instituto Universitário de Lisboa (ISCTE-IUL) e Doutor em Belas-Artes pela Universidade de Lisboa; professor na Faculdade de Belas-Artes dessa Universidade (FBAUL) na área Arte Multimídia e leciona nos diversos cursos de Licenciatura, Mestrado e Doutorado; professor nos cursos de doutorado em Ensino da Universidade do Porto; investigador integrado no Centro de Investigação e Estudos em BelasArtes (CIEBA). Coordenador do Congresso Internacional CSO: Criadores Sobre outras Obras $(2010,2011,2012,2013,2014,2015)$ e do Congresso Matéria-Prima, Práticas das Artes Visuais no Ensino Básico e Secundário (2012, 2013, 2014, 2015). Dirige as revistas acadêmicas Estúdio, Matéria-Prima, Cama e Croma. É membro de diversas Comissões Científicas como a do $23^{\circ}$ Congresso da APECV: Ensino de Artes Visuais: Identidade e Cultura no Século XXI (2011); ASC Conference: Art, Science, City (2013); do Congresso Vox Musei (2013) e do Conselho Editorial do International Journal of Cinema. Atua também como artista visual, tendo recebido o prêmio em Pintura da Academia Nacional de Belas-Artes de Portugal em 2004.

E-mail: joao.queiroz@fba.ul.pt

Currículo: http://www.fba.ul.pt/wp-content/uploads/2013/06/Jo\%C3\%A3o-Queiroz.pdf 